\title{
Marine natural products: a new wave of drugs?
}

The largely unexplored marine world that presumably harbors the most biodiversity may be the vastest resource to discover novel 'validated' structures with novel modes of action that cover biologically relevant chemical space. Several challenges, including the supply problem and target identification, need to be met for successful drug development of these often complex molecules; however, approaches are available to overcome the hurdles. Advances in technologies such as sampling strategies, nanoscale NMR for structure determination, total chemical synthesis, fermentation and biotechnology are all crucial to the success of marine natural products as drug leads. We illustrate the high degree of innovation in the field of marine natural products, which in our view will lead to a new wave of drugs that flow into the market and pharmacies in the future.

Nature is an ancient pharmacy that used to be the solitary source of therapeutics for the early eras. Yet, the renaissance of science and the deeper understanding of the pathology of several diseases enabled the design and synthesis of drug molecules for specific molecular targets, and, thus, shifted the attention from the 'natural pharmacy' to the purely synthetic drugs [1,2]. This attention was further biased towards synthetic drugs with the development of high-throughput screening technologies. The ability to test a large number of chemical entities in a certain assay at the same time required a larger and faster supply of compound libraries. Combinatorial chemistry fulfilled this latter requirement and preceded natural products in this specific obligation and thus was more tempting for drug discovery. However, relying on those 'faster' drug-discovery approaches that are irrelevant to our chiral world led to a concomitant 20 -year low number of new chemical entities in 2001 [3].

Natural products are often structurally complex compounds that possess a well-defined spatial orientation. Those chemical compounds evolved to interact efficiently with their biological targets; therefore, they occupy a biologically relevant chemical space and represent validated starting points for drug discovery. Accordingly, it is not surprising that $40 \%$ of the chemical scaffolds in the Dictionary of Natural Products occupy unprecedented chemical space that was not represented by synthetic compounds [4]. Moreover, the ingenuity of natural products allowed them to occupy a significant market share as well as a special preference by the consumers. Approximately half of all new drugs in the time frame reported are of natural product origin or designed on the basis of natural product structures [5] and approximately half of the 20 best-selling nonprotein drugs are related to natural products [6].

Almost all of the current natural productderived therapeutics have terrestrial origins. However, mining novel sources, such as the marine environment, will clear the way for chemical and biological novelties as well. A comparative analysis by Kong and co-workers showed that marine natural products are superior to terrestrial natural products in terms of chemical novelty [7]. The analysis, which compared molecular scaffolds reported in the Dictionary of Natural Products to those in the Dictionary of Marine Natural Products, showed that approximately $71 \%$ of the molecular scaffolds in the Dictionary of Marine Natural Products were exclusively utilized by marine organisms. In addition, marine organisms show higher incidence of significant bioactivity compared with terrestrial organisms. For example, in a National Cancer Institute preclinical cytotoxicity screen, approximately $1 \%$ of the tested marine samples showed anti-tumor potential versus $0.1 \%$ of the tested terrestrial samples [8]. Furthermore, the first marine drugs have successfully made it to the market, and there are several others in different phases of clinical trials. Mayer et al. have recently reviewed the current marine pharmaceutical pipeline [9]. Currently, there are four US FDA-approved marine or marine-derived drugs besides one additional drug registered in the EU $[9,10]$. Cytarabine (Ara-C) and vidarabine (Ara-A) (Figure I), the first FDA-approved marine-derived drugs, are synthetic pyrimidine and purine nucleosides, respectively, developed from naturally occurring nucleosides originally isolated from the Caribbean sponge Tethya

\section{Rana Montaser' \&} Hendrik Luesch ${ }^{\dagger 1}$

'Department of Medicinal Chemistry, University of Florida, Gainesville, FL 32610, USA

${ }^{\dagger}$ Author for correspondence:

Tel.: + I 3522737738

Fax: + | 352273774 |

E-mail: luesch@cop.ufl.edu 


\section{Key Term}

Secondary metabolite: Compound that is not involved in primary metabolism, but has a secondary role in the life of the producing organism, such as defensive chemicals. crypta. Cytarabine was approved by the FDA in 1969 as an anticancer drug, while vidarabine was approved in 1976 as an antiviral agent. More than 20 years later, ziconotide $\left(\right.$ Prialt $^{\circledR}$; FIGURE I) gained FDA approval in 2004 for the management of severe chronic pain. It is a synthetic equivalent of a naturally occurring peptide isolated from the venom of the cone snail Conus magus. Next came trabectedin (Yondelis ${ }^{\circledR}$; Figure I), the first marine anticancer agent to gain approval by the EU for the treatment of soft tissue sarcoma and relapsed ovarian cancer, and it is now awaiting FDA approval. Trabectedin is a marine alkaloid isolated from the marine tunicate Ecteinascidia turbinata that was registered in 2007 [9]. Eribulin mesylate (Halaven ${ }^{\text {TM }}$; Figure I) is the latest addition to the market from the marine environment, which gained FDA approval in November 2010 for metastatic breast cancer [10]. This totally synthesized drug is a structurally simplified macrocyclic ketone analogue of the potent cytotoxic compound halichondrin B, which was first isolated from the marine sponge Halichondria okadai in 1986. On their way to the market, there are 12 other marine or marine-derived drugs in clinical trials [9]. Examples include the cytotoxic compounds bryostatin 1 and the dolastatin derivatives soblidotin (auristatin PE; TZT-1027) and synthadotin (tasidotin; ILX-651; Figure 2). The former is a dolastatin 10 synthetic derivative in Phase III clinical trials, which is developed as an antibody-drug conjugate, while the latter is a synthetic dolastatin 15 derivative in Phase II clinical trials that is orally active. In addition, there is a continuous supply of auspicious candidates in the preclinical pipeline, which is continuously feeding the clinical pipeline. Promisingly, the number of new marine compounds reported each year is increasing, and more than 1000 new compounds with different potencies and biological activities have been reported each year for the past couple of years [11,12]. Marine natural products and their pharmacology have been reviewed by others [11-16] and we do not intend to comprehensively review this here. Rather, we focus on the fundamental reasons why we believe that the marine drug pipeline will rapidly increase over the next few years.

\section{Oceans contain tremendous biological diversity \& concomitant chemical diversity}

The resurgence of natural products-initiated drug discovery is tied to the exploration of novel natural sources and organisms, such as those in the marine world, which covers $70 \%$ of the earth's surface and represents the largest unexplored wealthy resource. The first Census of Marine Life (2000-2010) has just completed a decade inventory that revealed an astounding level of biodiversity. With a focus on waters that are closer to the coastline in the explored countries and, thus, are expected to be well documented, the project amplified the estimate of known marine species from approximately 230,000 to nearly 250,000. Moreover, they extrapolated their findings to at least a million of marine species and tens or even hundreds of millions of microbial species [201]. Simultaneously, Venter has focused attention on the huge biodiversity found in the marine microbial world. The first sampling expedition in the ocean exploration genome project (Global Ocean Sampling Expedition, 2003) has led to the identification of 1.2 million new genes and has doubled the number of protein sequences in the NIH's GenBank [17,18].

Recently, Wolfe-Simon and co-workers reported the adaptability of a Mono Lake bacterium to its arsenic-rich environment, which led to the incorporation of arsenate into its macromolecules instead of phosphate [19]. Although the report is open to significant debate, if this finding is genuine, it highlights the striking capability of microbes to adapt to their environment, leading to unexpected biochemical reactions. A similar concept may be applicable to the marine environment, where the harsh growth conditions trigger novel techniques and biochemical pathways. For example, the deepsea hydrothermal vents represent extreme environments (temperature up to $400^{\circ} \mathrm{C}$, absence of light, extreme $\mathrm{pH}$ and pressure, and high levels of normally toxic abiotic chemicals such as $\mathrm{H}_{2} \mathrm{~S}$ ), and, surprisingly, enclose high densities of biologically diverse communities with distinct metabolisms [20]. Loihichelins A-F (FIGUre 3) are examples of novel peptide siderophores obtained from the basalt-weathering marine bacterium Halomonas sp. LOB-5, originally isolated from Loihi Seamount east of Hawaii [21]. Similarly, palmerolide A (FIgUre 3) represents another profound example for a potent anticancer compound $\left(\mathrm{LC}_{50}=18 \mathrm{nM}\right.$ in UACC-62 melanoma cell line) isolated from a cold-adapted circumpolar tunicate from Antarctica [22]. Also, symbiosis is a well-known phenomenon in the marine environment that results from nutritional scarcity and the need for chemical defense in organisms that lack physical defensive 
techniques. A clear example is the symbiotic interaction between Prochloron spp. bacteria and its ascidian animal host; the bacteria provide the host with photosynthate and defensive chemicals, and obtain waste nitrogen in return [23]. Patellamides (FIgure 3) are cytotoxic secondary metabolites initially isolated from the marine tunicate Lissoclinum patella [24], but the associated bacterium was proven to be the true producer [25]. Similarly, recent studies showed that the bacterial symbiont Candidatus Endobugula sertula is the source of the cytotoxic bryostatins that were discovered from the marine bryozoan Bugula neritina (FıGure 2) [26,27]. It was shown that the bacterial aggregates produce a coating of bryostatins around the bryozoan larvae for protection against predators. Hence, the marine environment represents a unique resource that encloses a massive biological diversity, which will potentially lead to unique biologically active chemical diversity that we can translate into novel biomedicines.

\section{Oceans harbor unique chemical entities with novel targets \& mechanisms of action}

The marine habitat is a prolific source of bioactive secondary metabolites with the potential to treat several diseases. Besides the chemical novelty associated with those compounds, some of them possess novel mechanisms of action as well. The recently approved marine drugs represent noteworthy examples. Ziconotide (Prialt; Figure I) possesses a potent analgesic effect, which is mediated through a completely novel mechanism of action; it reversibly blocks $\mathrm{N}$-type voltage-sensitive calcium channels, inhibiting the activity of a subset of neurons including pain-sensing primary nociceptors [28]. Ziconotide is the first $\mathrm{N}$-type calcium-channel blocker and it is also the first marine-derived peptide drug on the market $[9,29]$. Moreover, the discovery of this novel mechanism of action proved the key role of $\mathrm{N}$-type calcium channels in signal-regulation innociceptive neurons, and further validated those channels as drug targets [28,29]. Strikingly, ziconotide is 1000 times more potent than morphine and it does not produce tolerance, which is well known with opiate-based therapies [30]. The anticancer drug trabectedin (Yondelis; Figure I) also shows a unique and complex mechanism of action. It binds to the DNA minor groove causing DNA damage and distinctively interferes with the transcription-coupled nucleotide repair system,

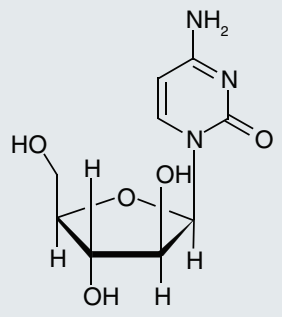

(Cytosar- $\left.\bigcup^{\circledR}\right)$

FDA Approval 1969

Cancer

Ziconotide

(Prialt ${ }^{\circledR}$ )

FDA Approval 2004

Pain
Cytarabine, Ara-C

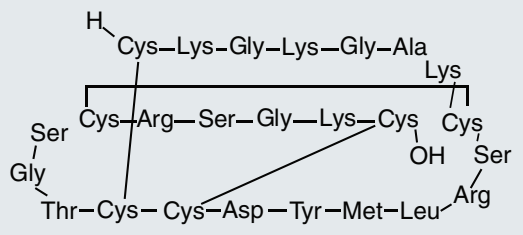

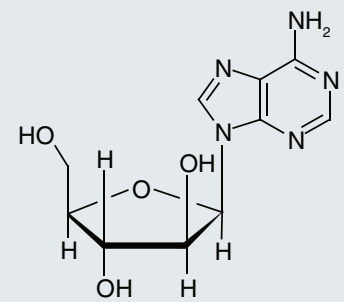

Vidrabine, Ara-A (Vira-A ${ }^{\circledR}$ )

FDA Approval 1976

Antiviral

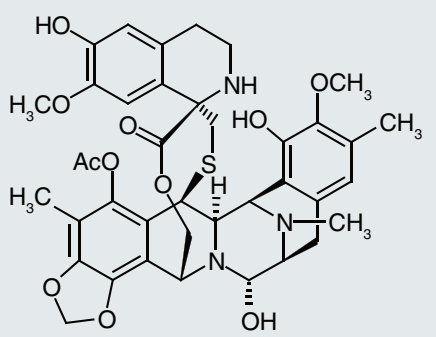

Trabectedin, ET-743 (Yondelis ${ }^{\circledR}$ )

EU Registered 2007

Cancer

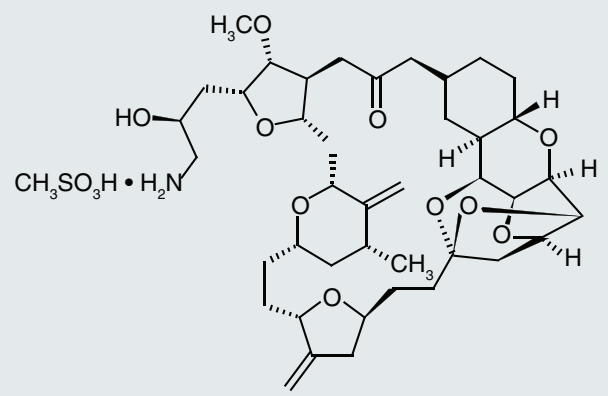

Eribulin mesylate, E7389

(Halaven $^{\text {TM }}$ )

FDA Approval 2010

Cancer

Figure 1. Marine drugs on the market and conditions treated.

therefore preferably inducing apoptosis in cancer cells that show highly accelerated gene expression compared with normal cells [31]. Likewise, the recently approved anticancer marine drug eribulin mesylate (Halaven; Figure I) acts by a novel microtubule-targeting mechanism, where it aggregates tubulin and selectively blocks microtubule growth in a fashion that is discrete from other antimitotic drugs [32].

Among the clinical and preclinical pipelines, there are some notable examples for marine bioactive compounds with novel mechanisms of 


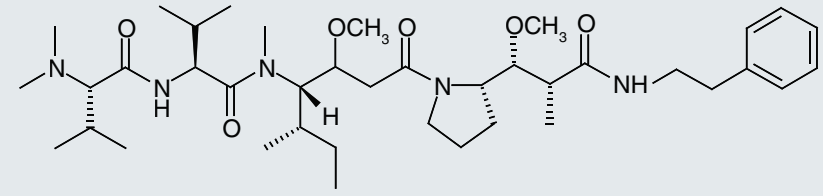

Soblitodin (Auristatin PE; TZT-1027)

Phase II/III (as monoclonal antibody conjugate)

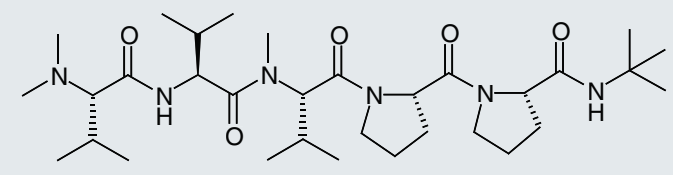

Synthadotin (Tasidotin; ILX-651)

Phase II

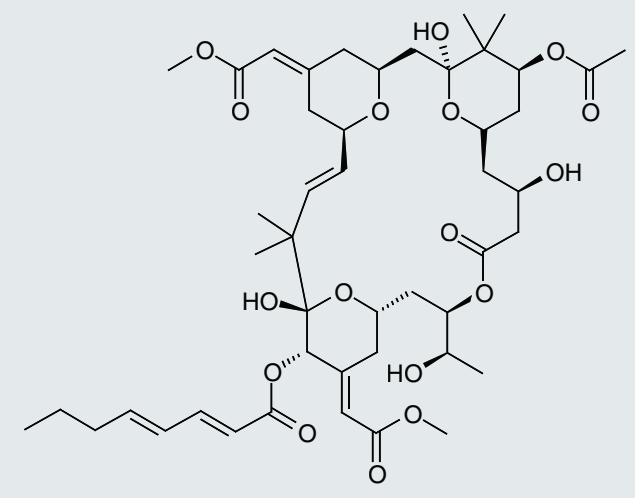

Bryostatin 1

Phase I

Figure 2. Examples of marine natural products in different phases of clinical trials. from achieving their maximum size, unlike other known antimicrotubule compounds, which cause nearly complete loss of cytoplasmic microtubules and mitotic spindles in the same fungal cells. Notably, spongistatin 1 also shows a significantly potent cytotoxic activity in mammalian cells, which was attributed to its antimitotic effect [38], as well as its ability to induce apoptosis and $\mathrm{x}$-linked inhibitor of apoptosis protein degradation causing cell death [39]. Furthermore, some marine bioactive compounds that share mechanisms of action with other known drugs proved to be the most potent among their classes. For example, the marine actinomycete-derived cytotoxic secondary metabolite salinosporamide $\mathrm{A}$, which is currently in clinical trials, is one of the most potent proteasome inhibitors (FIGURE 4) [40].

The continuous efforts in the field of marine drug discovery will potentially reveal more potent bioactive compounds with unusual mechanisms of action. From our group alone, two cytotoxic compounds fall into this category. Apratoxin A is a potent cytotoxin originally isolated from a marine cyanobacterium from Guam (FIGURE 4) [41]. Its nanomolar antiproliferative activity was associated with a unique differential cytotoxicity profile in the National Cancer Institute's 60-cell-line screen. Extensive mechanism-of-action studies by our group revealed that apratoxin A reversibly inhibits the secretory pathway for several cancer-associated receptors by interfering with cotranslational translocation [42]. This was the first report for an antitumor compound to act by this mechanism. Moreover, the activity of apratoxin A as a reversible secretory pathway modulator represents a valuable pharmacological tool for investigating this pathway. Also, the cyclic depsipeptide largazole, isolated from a cyanobacterium of the genus Symploca, is one of the most potent class I histone deacetylase inhibitors, and it is also the first known cyanobacterial secondary metabolite that encloses a thioester (FIgURE 4) [43,44].

\section{Drug discovery from the sea: advancements toward better chemical $\&$ biological characterization of marine natural products}

The path for drug discovery from natural sources faces several challenges, starting with the access to the marine environment followed by chemical and biological characterizations of the promising natural products, which are often isolated in minute amounts. Consequently, advancements 
<smiles>[R]N[C@@H](C(=O)N[C@@H](CO)C(=O)N[C@@H](CCC(N)=O)C(=O)NC(CO)C(=O)NC(CCCN(O)C(C)=O)C(=O)NC(=CC)C(=O)N[C@@H](CO)C(=O)N[C@H]1CCCN(O)C1=O)C(O)C(=O)O</smiles>

$\mathrm{R}=$

A<smiles>CCCCCCCCCCC(C)=O</smiles>

B<smiles>CCCCCCCCCCC(O)CC(C)=O</smiles>

C<smiles>CCCCCCC/C=C/CCCC(C)=O</smiles>

D<smiles>CCCCCCCCCCCCC(C)=O</smiles>

E<smiles>CCCCCC/C=C/CCCCCCC(C)=O</smiles><smiles>CCCCCCCCCCCCCC(C)=O</smiles>

Loihichelins A-F

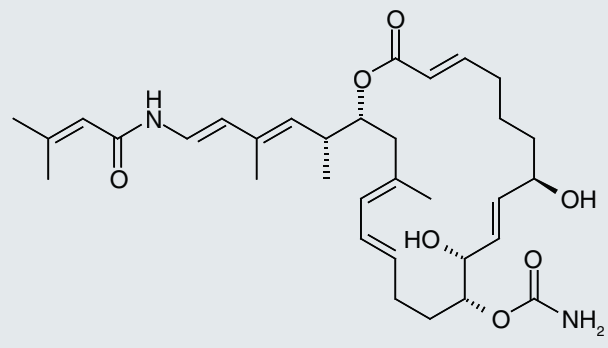

Palmerolide A

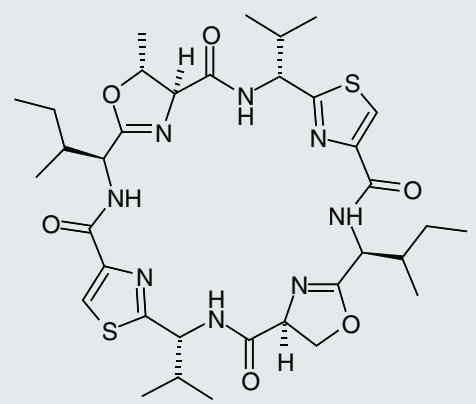

Patellamide A

Figure 3. Examples of bioactive secondary metabolites produced by marine organisms adapted to their extreme environmental conditions or arising from symbiotic interactions.

in sampling techniques, structure determination strategies as well as target-identification methods represent crucial steps in marine drug discovery.

\section{Sampling techniques}

Perhaps one of the main reasons that prevented the ocean from being explored for a very long time was that its sampling requires more specialized techniques and equipments. Numerous compounds were reported from easy-to-access near-shore collected marine samples; however, other hard-to-access regions in the ocean could be enclosing unidentified macro- and microorganisms and, consequently, novel therapeutics. Fenical and co-workers dedicated their efforts to searching the hard-to-access deep-sea marine sediments for the presence of promising antibiotics, based on the long-known antibiotic productivity of the soil-inhabiting bacteria. They were able to design a device to obtain samples from the sea bottom at depth of greater than $2000 \mathrm{~m}$, using relatively small boats as a solution to the access challenge [45]. As a result, they succeeded in discovering phylogenetically novel marine actinomycete strains, including the prolific source of bioactive secondary metabolites Salinispora tropica, which produced the potent proteasome inhibitor salinosporamide A (Figure 4) [40,45].

\section{- Nanomole structure determination}

While NMR spectroscopy continued to be the vital element for structure elucidation, its low sensitivity compared with other techniques, 


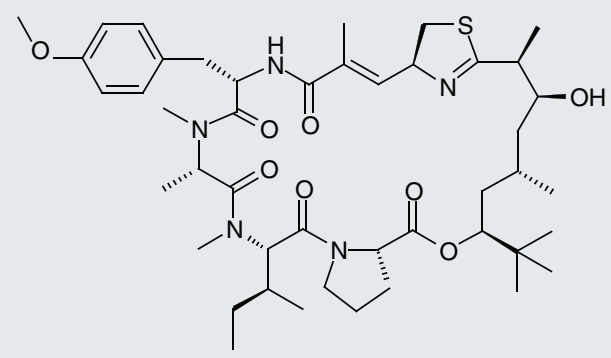

Apratoxin A

(Secretory pathway inhibitor)

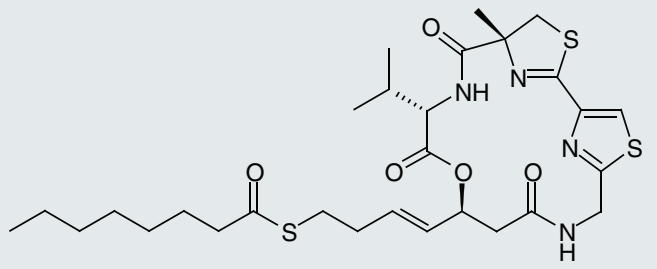

Largazole (Prodrug)

(Histone deacetylase inhibitor)

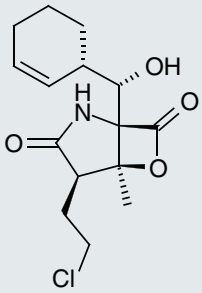

Salinosporamide A (Proteasome inhibitor)<smiles>CN1C(=S)c2cc(C(N)=O)cc3c(N)c(Cl)c(N)c1c23</smiles>

Ammosamide A (Myosin function inhibitor)

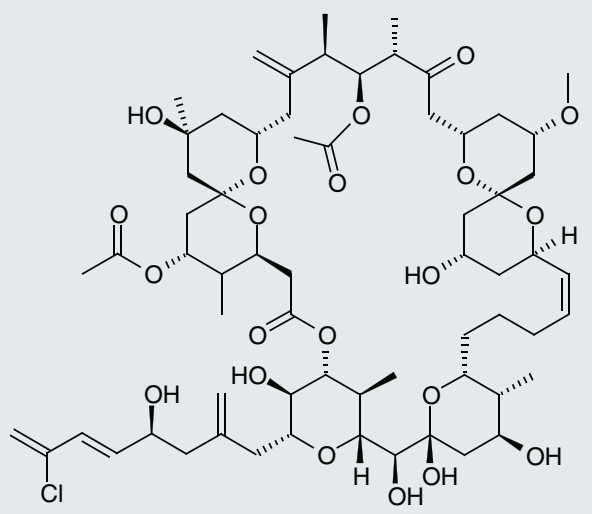

Spongistatin 1

(Tubulin polymerization inhibitor)
Figure 4. Examples of highly potent marine natural products, with unusual or novel mechanisms of action, with promising biomedical applications. such as MS, for example, remained a limiting issue. Until a few years ago, more than a micromole of a compound was essential to completely elucidate its structure. Recent advances in NMR structure elucidation methodologies have changed this obligation and several recent reports explored minor amounts of natural products on a nanomole [46] or even picomole scale [47]. Molinski has recently reviewed those advances [46] and showed an evident example for the significant contribution of microscale methodology to more efficient chemical characterization of rare marine samples by his group. They isolated the antifungal and cytostatic macrolides phorboxazoles A (95.1 mg) and B (40.5 mg) from the marine sponge Phorbas sp. collected off Muiron Island in Western Australia in 1995 (Figure 5) [48]. With the use of a 5-mm cryoprobe, phorbasides A-E were later discovered from minor chromatography side fractions (0.78-3 mg) (Figure 5) [49]. Furthermore, with the availability of the more sensitive $1.7-\mathrm{mm}$, $600-\mathrm{MHz}$ cryomicroprobe, they continued to investigate the chemical diversity in that marine organism and successfully reported the structures of more minor compounds at the nanomole scale, including four more phorbaside analogues $(7-16 \mu \mathrm{g})$ [50], hemi-phorboxazole A (16.5 $\mu \mathrm{g}, 28 \mathrm{nmol})$ [51] and the new macrolide muironolide A (90 $\mu \mathrm{g}, 152 \mathrm{nmol})$ (FIGURE 5), which represented a new carbon skeleton with unprecedented features [52]. Beside nanomolescale NMR spectroscopy, circular dichroism, mass spectrometry as well as chemical synthesis enabled them to fully solve those structures including the stereochemical assignments. Recently, Fellenberg et al. narrowed the working limits of NMR spectroscopy even further by recording spectra of picomole amounts of oligosaccharides, using special sample preparation techniques and instrument setup [47]. Furthermore, a revolutionary introduction of an enhanced imaging technique for organic structure determination such as atomic force microscopy has been reported in the past 2 years, with the advantage of producing clear molecular images that can help determine the correct structure of unknown organic molecules. For example, Gross et al. [53] have recently succeeded in using noncontact atomic force microscopy to visualize cephalandole A [54,55], which eventually led to unambiguous confirmation of one of the four optional structures proposed for it. Although the success of this method remains restricted to planar structures, fast technological 
advances keep the door open for possible future modifications that could expand the limits of this technique.

\section{Target identification}

Phenotypic screening has gained academic as well as industrial attention to discover drug leads that modulate biological pathways [56]. Once a hit compound has been characterized in one of those screens, the identification of its cellular target and mechanism of action remains a bottleneck for its development into a drug. This mechanistic knowledge is crucial to anticipate the potential side effects and, consequently, to avoid costly clinical failures. It also allows for lead optimization and provides biomarkers for preclinical and clinical trials. Several important developments in drug target-identification strategies facilitated this step and, thus, increased the chances for drug discovery and development [56-58]. Target-identification approaches following a phenotypic screen fall into two categories: direct methods, such as affinity chromatography, expression cloning and protein microarrays; and indirect methods, such as global profiling techniques based on genomics, proteomics or metabolomics [57].

Affinity chromatography is one of the classical methods for target identification. However, there are several other modifications that try to overcome the difficulties associated with this technique, which usually requires the introduction of a label. One of the advanced label-free strategies is known as 'drug affinity responsive target stability', which is based on the enhanced stabilization of the target protein against proteolysis by binding to its substrate or bioactive compound [59]. Digesting away nontarget proteins would then lead to target protein enrichment and further detection. The molecular target of didemnin B, for example, was originally identified using affinity purification methods [33] and later confirmed using drug affinity responsive target stability [60], providing further evidence for the applicability of this novel technique.

Theonellamides A-F are antifungal bicyclic dodecapeptides isolated from the marine sponge Theonella sp. [61,62]. Nishimura et al. have succeeded in identifying the mechanism of action of theonellamides using several direct and indirect techniques [63]. Mainly by employing chemical-genomic profiling in fission yeast, as well as fluorescent labeling to determine subcellular localization of the compound, they were able to

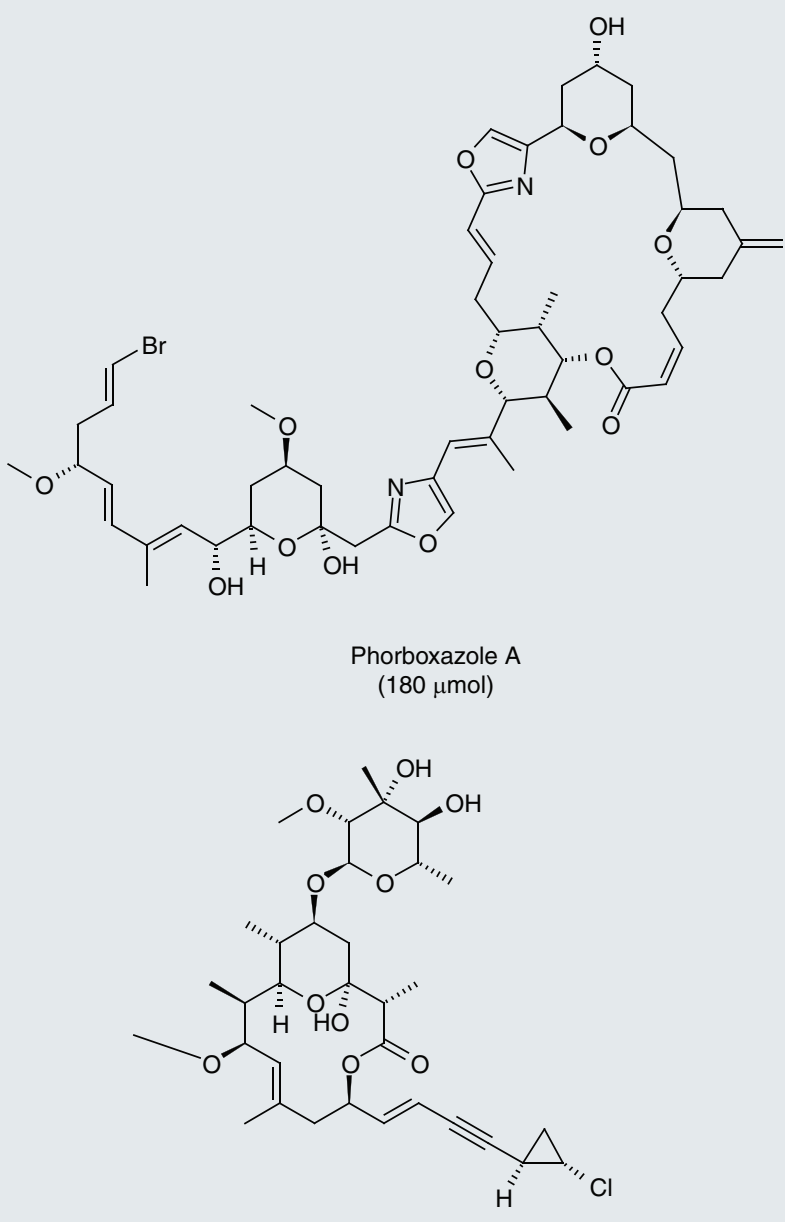

Phorbaside A $(1.5 \mu \mathrm{mol})$

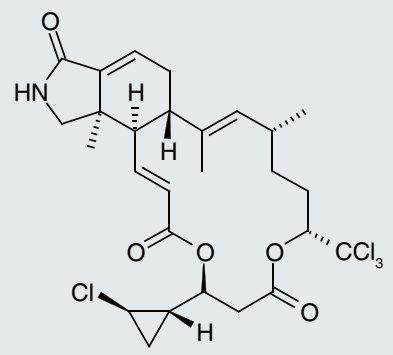

Muironolide A $(0.15 \mu \mathrm{mol})$

Figure 5. Macrolide marine secondary metabolites from the marine sponge Phorbas sp. Nanomole structure-determination techniques allowed for more efficient exploration of this sample revealing unique metabolites.

Data from [46].

identify ergosterol, the primary sterol in fungal cell membrane, as the direct target of theonellamides in fission yeast. However, the sterol binding action of theonellamides differs from 


\section{Key Terms}

\section{Supply problem: The} challenge of ensuring continuous large-scale production of a bioactive compound for clinical trials, and most importantly for continuous supply to the market.

Gene cluster: Set of genes encoding the same or similar products. For example, a biosynthetic gene cluster will encode for a set of biosynthetic enzymes that undergo linked enzymatic reactions to produce a biochemical compound.

Genome mining: Process of searching the genome for DNA sequences encoding the biosynthesis of novel compounds. other known sterol binders, indicating that those marine secondary metabolites represent a previously unknown class of sterol-binding molecules. Also, the target responsible for the cytotoxicity of the marine alkaloids ammosamides was identified through an innovative labeling technique [36]. The preparation of immunoaffinity fluorescent probes for ammosamides (Figure 4) allowed for conducting molecular as well as cellular studies with the same probe, which led to the characterization of myosin as the directly interacting target.

The potent cytotoxin apratoxin A was also discovered through a phenotypic cell viability screen in 2001 by Luesch et al. (Figure 4) [41]. Chen and Forsyth reported the first total synthesis of this compound 2 years later [64]. The first insight into its mechanism of action was achieved in 2006 through a functional genomics approach [65], followed by biochemical and proteomics approaches $[42,66]$. Apratoxin A reversibly inhibits the secretory pathway for several cancer-associated receptors by interfering with cotranslational translocation [65], which has not yet been exploited for anticancer drug development. In conclusion, the innovation in the field of drug target identification potentiates the chances for a promising marine-derived compound to be developed further.

Solutions to the 'supply issue': crossing the bridge between marine drug leads $\&$ the market with the help of advanced technologies

In order to conduct preclinical and clinical trials and further develop a promising compound into a marketed drug, continuous supply is a necessity. The supply problem is one of the major challenges facing marine natural product drug discovery. However, some remarkable solutions are recently provided to this critical issue and more supply relief is offered by the rapidly moving progress in several technologies. Examples include advances in synthetic chemistry and fermentation, as well as biotechnology.

\section{- Total chemical synthesis}

Despite the characteristic structural complexity associated with marine natural products, there is a remarkable development in their total chemical synthesis, which is often reported shortly after their discovery. The success in developing a feasible approach for total chemical synthesis of a bioactive molecule has two major advantages: first, it ensures a large-scale supply of a rare bioactive compound; second, it allows for further structure-activity relationship (SAR) studies and lead optimization. However, in order to enhance the latter advantage, identification of the mechanism of action and the interacting target of the lead compound is important. For example, the complex structure of the potent marine cytotoxic compound bryostatin 1 (Figure 2), which represents a challenge for synthetic chemists, was further simplified to a more potent analogue based on the known interactions with the target protein [67], and a simpler structure leads to a simpler total chemical synthetic approach. Likewise, several efforts towards the total synthesis of spongistatins have been tackled by several groups, and Smith's laboratory was able to obtain $1 \mathrm{~g}$ of totally synthesized spongistatin 1 (Figure 4) [68]. Notably, synthetic studies performed by Paterson's group [69], Heathcock et al. [70] and, recently, by Smith and co-workers [71] revealed some essential SAR features, which could lead to a potent simplified analogue.

Halichondrin B is a potent cytotoxic macrolide isolated from the sea sponge H. okadai in 1986, and represents a complex marine natural product with 32 stereocenters [72]. Its effect against microtubule assembly was determined by analyzing differential cytotoxicity patterns in human tumor cell lines [73]. In 1992, Kishi and his team succeeded in totally synthesizing this compound [74]. Considering its mechanism of action, further SAR studies brought about the more potent, structurally simpler and more stable ketone analogue Eribulin (E7389), with 19 stereocenters. Eribulin mesylate (Halaven; Figure I) was approved by the FDA in November 2010 for metastatic breast cancer, becoming the fourth marine-derived drug on the market [10]. Although this drug is supplied through a 62-step synthesis [75], reliable chemistry combined with drug safety and efficacy drove this marinederived drug to the market. The success in ensuring a continuous supply for such a potent and very complex marine compound emphasizes that worries about the supply issue should not hamper the efforts in exploring such a wealthy resource.

\section{Fermentation}

Besides total chemical synthesis, fermentation is another potential solution to the supply issue in some cases. The metabolic potential of microbes plays a fundamental role in human medicine. One milliliter of sea water contains $10^{6}$ microbes. This number escalates as we examine marine 
sediments; $1 \mathrm{~cm}^{3}$ of ocean bottom sediment contains $10^{9}$ microbes. In a study performed by Long and Azam, more than half of the examined marine bacterial isolates produced antimicrobial compounds and they found this trait to be more common in surface-associated bacteria than in free-living bacteria [76]. In addition, the marine environment encloses phylogenetically novel microbial groups [45] and, therefore, represents a promising reservoir for drug discovery.

Despite the fact that most of the marine microbes are hard to cultivate in the laboratory, the few culturable strains have already produced significant bioactive compounds that are on their way to the market. Salinosporamide A was discovered from the novel culturable marine-sediment actinomycete strain $S$. tropica (Figure 4) [40]. Although this cytotoxic compound was synthesized, its ongoing clinical studies rely on large-scale saline fermentation for continuous drug supply. It is worth mentioning here that this potent proteasome inhibitor entered clinical studies only 3 years after its initial discovery [40]. Fermentation also plays an important role in the large-scale supply of the anticancer drug trabectedin (Yondelis). The current industrial process for the production of trabectedin by PharmaMar comprises the initial large-scale fermentation of the starting material cyanosafracin B from Pseudomonas fluorescens, followed by semisynthetic steps to reach the final drug [77]. This drug-development process parallels that of paclitaxel $\left(\mathrm{Taxol}^{\circledR}\right)$. The initial large-scale supply of paclitaxel relied on semisynthesis starting from the precursor 10-desacetylbaccatin III obtained from the needles of Taxus baccata [78]. Currently, Phyton Biotech is supplying Bristol-Myers Squibb with paclitaxel obtained through large-scale plant cell culture technologies [79].

Genomic studies showed that the microbial gene clusters that express bioactive secondary metabolites under their natural competitive environmental conditions can remain silent under unnatural laboratory conditions. Mixed fermentation is validated as an effective approach to better explore the metabolic potential of cultivable microbes [80]. For example, the previously unexpressed biosynthetic pathways that produced the new diterpenoids libertellenones A-D were triggered by cultivating the marine fungus Libertella sp. with a marine bacterium [81], as was the case with the discovery of marinamides $\mathrm{A}$ and $\mathrm{B}$ by co-culturing two marine fungi [82]. Similarly, Watanabe's group investigated the synergistic production of the blue metabolite pyocyanin in mixed marine microbial cultures, where the compound was not detected in pure cultures [83]. Moreover, mixed fermentation could also enhance the production of secondary metabolites that were not detected before because of their below-detection limit quantities. Emericellamides A and B that were not detected by normal LC-MS analysis in the pure culture of Emericella sp. showed 100-fold enrichment upon inoculating the bacterial culture with the marine actinomycete Salinispora arenicola [84].

\section{- Biotechnology}

Biotechnology is revolutionizing the field of marine natural products. Advances in analytical tools as well as molecular biology facilitate the identification of the true producer of a secondary metabolite from a symbiotic assemblage, and enable scientists to further explore the oceanic microbial diversity and prioritize organisms for drug discovery. Moreover, those advances escort the characterization of several biosynthetic gene clusters and pathways and ultimately allow for their manipulation [85]. Microbial chemical factories are now being explored for the easy and more efficient biosynthesis of tediously fully synthesized lead compounds, where biosynthetic genetic engineering [85,86], as well as in vitro multienzyme synthesis [87,88], are currently emerging approaches in the field of drug development and optimization. The cost of genomic sequencing is sharply decreasing. Whole-genome sequencing of a microorganism depicts its biosynthetic potential, where it guides the identification of gene clusters for the already known compounds. It also guides genome mining as a new drugdiscovery approach, where putative chemical structures of previously unobserved natural products could be predicted $[85,89]$.

The genome of the marine actinomycete S. tropica was fully sequenced in 2007 , to be the first fully sequenced genome of a marine actinobacterium [90]. Strikingly, the results revealed a complex secondary metabolome, where approximately $10 \%$ of the genome is dedicated to natural product assembly; a percentage that is greater than other natural product-producing actinomycetes. The results also exposed a remarkably high diversity of polyketide synthases (PKSs), as well as nonribosomal peptide synthetases (NRPSs) and hybrid PKS/NRPS pathways. Three different compound classes were previously identified from this bacterium: salinosporamides [11], sporolides [92] and lymphostin [90,93]. By correlating 
the number of discovered compounds and classes with the high number of biosynthetic pathways in S. tropica, it was clear that the biosynthetic capacity of this organism is not yet fully accessed [90]. As a new drug-discovery approach, genome-guided natural product discovery combined with natural product chemistry led to the identification of the novel polyene macrolactam salinilactam A. In addition, identifying the biosynthetic pathway of salinosporamide A allowed for conducting SAR studies through the engineering of 'unnatural natural' analogues. Precursor-directed biosynthesis and semisynthesis produced bromine and iodine-substituted derivatives [94], while genetic engineering was used to produce fluorosalinosporamide derivatives [95]. Mutasynthetic studies were used to test the importance of the cyclohexenyl group as well as the hydroxy substituent at the cycloalkenyl side chain of salinosporamide A (FIGURE 4). All of these experiments revealed the contribution of the cyclohexenyl group as well as the hydroxylation to the high potency of salinosporamide A, and showed that substituting chlorine with fluorine significantly extended the duration of action of this compound on the proteasome.

A similar precursor-directed biosynthesis effort was carried out after identifying the biosynthetic enzymes involved in the production of the clinical candidates cryptophycins [96], which gave rise to a new collection of analogues. Cryptophycins are a group of more than 25 structurally related cytotoxic peptolides produced by a lichen cyanobacterial symbiont. Despite their initial identification from terrestrial bacterial strains, the first marine cryptophycin analogue arenastatin A (cryptophycin 24) was later isolated from an Okinawan marine sponge [97]. The inherent flexibility of the identified biosynthetic enzymes allowed for the acceptance of structurally diverse starter units releasing novel depsipeptide natural products. Remarkably, the identification of the genes encoding the tailoring enzymes responsible for macrocyclization (Crp TE) and stereospecific epoxidation (CrpE CYP450) gave a key solution to two major challenges in the total synthesis of those peptolides. It was revealed that a tandem chemoenzymatic reaction utilizing the biocatalysts Crp TE and CrpE can efficiently cyclize and epoxidize linear synthetic cryptophycins [98] and consequently gives wider chances for the development, optimization and efficient synthesis of those bioactive natural scaffolds. In addition, as chemoenzymatic synthesis proved its efficiency in totally synthesizing bioactive natural products [99], in vitro multienzyme synthesis has also proved to be a powerful alternative to conventional chemical synthesis and metabolic engineering [87]. Moore and co-workers have succeeded in assembling the first complete in vitro type II PKS enzymatic pathway to totally synthesize enterocin polyketides [100]. The total synthesis was a single-vessel reaction that used only purified enzymes (biocatalysts), and involved the 'favorskiiase' flavoprotein EncM, which catalyzes the unique favorskii-like rearrangement of linear polycarbonyl compounds to the tricyclic enterocin target scaffold. Their results proved the feasibility of this innovation as a tackled approach to overcome structural complexity-associated synthetic problems.

Genome sequencing again guides the development of novel methods and techniques for the benefit of natural product drug discovery. Recently, Sherman and co-workers developed a web-based program (Natural Product searcher), which offers a rapid method to scan a microbial genome sequence for potential natural product biosynthetic clusters [101]. The scan results are predictions for structural assembly encoded by a PKS, NRPS or hybrid NRPS/PKS clusters, and the output secondary metabolic structures are obtained in a text format compatible with conventional chemical software programs. Similar results obtained by Mohanty et al. from an in silico analysis of PKS gene clusters further supported the promising potential for natural product discovery by genome mining [102]

\section{Future perspective}

Over half of all drugs are based on terrestrial natural products scaffolds. Despite this fact, natural products have been neglected for drug discovery with the advent of high-throughput screening technology. However, since assaying large synthetic libraries that are irrelevant to our chiral world has not lived up to the initial promise of delivering drug candidates, there has been a renaissance of natural products as leads for drug discovery, particularly if novel sources/organisms can be uncovered. The largely unexplored marine world that presumably harbors the most biodiversity may be the vastest resource to discover novel 'validated' structures with novel modes of action that cover biologically relevant chemical space. Several challenges, including the supply problem and target identification, need to be met for successful drug development of these oftentimes complex structures. Can the hurdles associated with developing these molecules be overcome? 


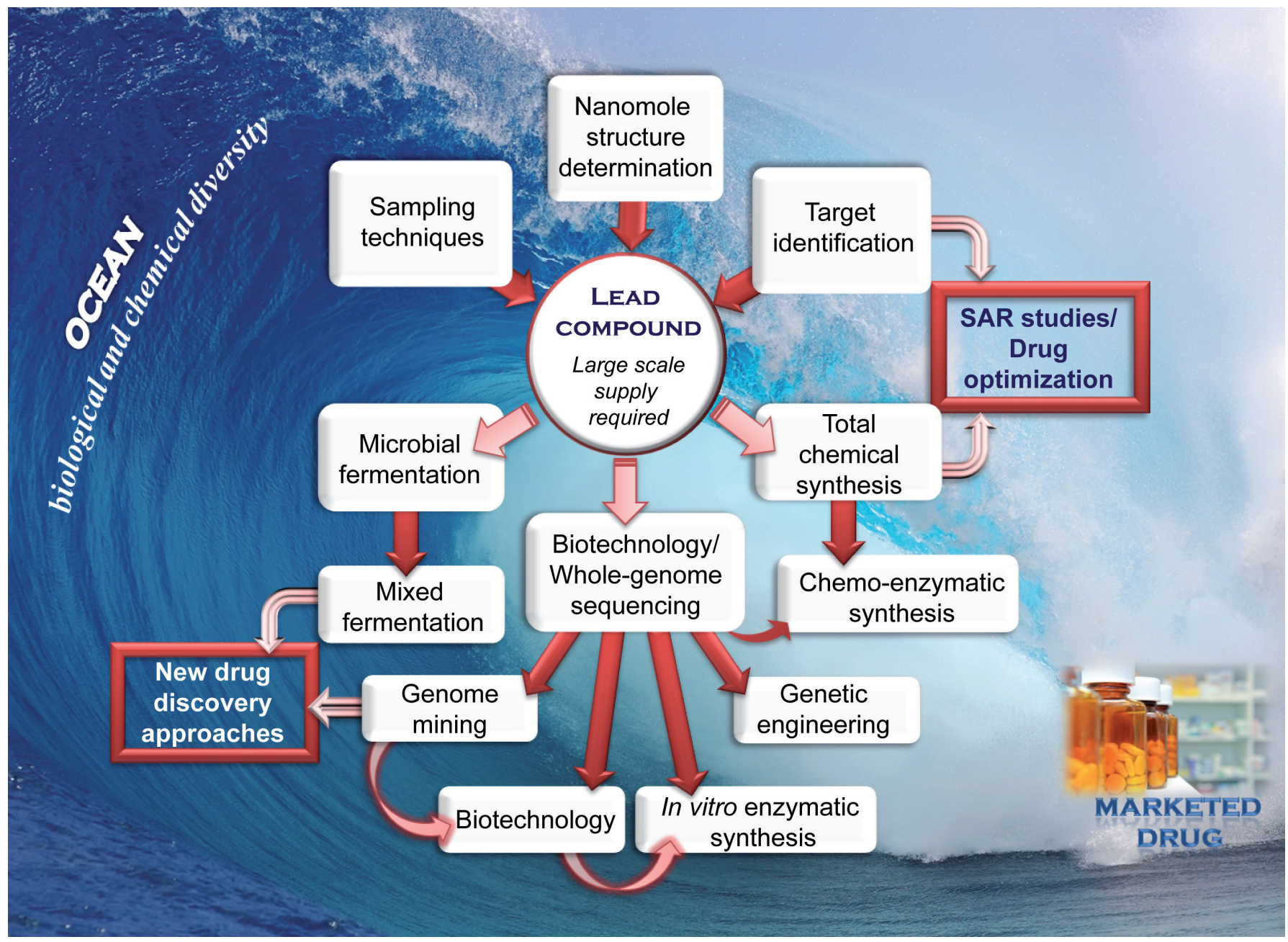

Figure 6. Predicted a new wave of drugs from the ocean, achieved through the synergistic combination of advanced technologies.

SAR: Structure-activity relationship.

The answer is yes, because the first marine natural products have entered the drug market and several hopeful candidates are already in advanced stages. Can the oceans provide a robust pipeline of marine drugs? Advances in technologies such as sampling strategies, nanoscale NMR for structure determination, total chemical synthesis, biosynthesis and genetic engineering are all crucial to the success of marine natural products as drug leads. Whole-genome sequencing will become a routine method to predict biosynthetic and drug potential. In our view, the high degree of innovation in the field of marine natural products will lead to successful marine drug discovery and development (FIgure 6), and provides grounds for our optimism that marine natural products will form a new wave of drugs that flow into the market and pharmacies in the future.

\section{Financial \& competing interests disclosure}

Marine natural products research in the authors' laboratory is supported by the NIH, NIGMS grant P41GM806210 and NCI grants R01CA138544 and R21CA133681, and the Bankhead-Coley Cancer Research Program, grant 1BG07. Hendrik Luesch is an associate professor at the University of Florida and Rana Montaser is a graduate student in his research group. Luesch has received grants to study the chemistry and biology of largazoles and apratoxins and is inventor of patent applications related to these compounds. The authors have no other relevant affiliations or financial involvement with any organization or entity with a financial interest in or financial conflict with the subject matter or materials discussed in the manuscript apart from those disclosed.

No writing assistance was utilized in the production of this manuscript. 
Executive summary

\section{Uniqueness of marine natural products}

- Natural products represent validated starting points for drug discovery, since they occupy biologically relevant chemical space.

- There is an increasing need for novel therapeutics, especially because of the existence of currently incurable diseases as well as emerging microbial resistance to current therapeutics.

- The marine environment covers $70 \%$ of the earth's surface, is characterized by unique growth conditions and encloses massive biodiversity.

- Biodiversity presumably produces chemodiversity as well, giving wider opportunity for discovering novel therapeutics with novel mechanisms of action.

\section{Spectacular opportunities for marine drug discovery}

- Marine natural products proved their efficacy against a wide array of diseases, with some possessing novel mechanisms of action and others being the most potent among their inhibitor classes.

- Currently, there are four marine-derived drugs on the market and 12 more in different phases of clinical trials.

- Innovations in several fields overcome the hurdles associated with marine drug discovery and development.

- Advancements in several methodologies, such as sampling techniques, nanomole structure determination as well as genome sequencing and mining, enhance the efficiency of exploring marine samples for novel therapeutics.

- Several advanced techniques proved to be successful in overcoming the supply problem, including total chemical synthesis and microbial fermentation, as well as molecular biology tools.

- Numerous compounds at various stages of development that successfully utilize those innovations highlight marine natural products as a new wave of drugs.

\section{Bibliography}

Papers of special note have been highlighted as:

- of interest

-. of considerable interest

1 Houghten RA. Combinatorial libraries. Finding the needle in the haystack. Curr. Biol. 4, 564-567 (1994).

2 Ortholand JY, Ganesan A. Natural products and combinatorial chemistry: back to the future. Curr. Opin. Chem. Biol. 8, 271-280 (2004).

3 Class S. Pharma overview. Chem. Eng. News 80, 39-49 (2002).

4 Henkel T, Brunne RM, Müller H, Reichel F. Statistical investigation into the structural complementarity of natural products and synthetic compounds. Angew. Chem. Int. Ed. 38, 643-647 (1999).

5 Newman DJ, Cragg GM. Natural products as sources of new drugs over the last 25 years. J. Nat. Prod. 70, 461-477 (2007).

6 Harvey A. Strategies for discovering drugs from previously unexplored natural products. Drug Discov. Today 5, 294-300 (2000).

7 Kong DX, Jiang YY, Zhang HY. Marine natural products as sources of novel scaffolds: achievement and concern. Drug Discov. Today 15, 884-886 (2010).

8 Munro MHG, Blunt JW, Dumdei EJ, Hickford SJH et al. The discovery and development of marine compounds with pharmaceutical potential. J. Biotechnol. 70, 15-25 (1999).
9 Mayer AMS, Glaser KB, Cuevas C et al. The odyssey of marine pharmaceuticals: a current pipeline perspective. Trends Pharmacol. Sci. 31, 255-265 (2010).

- Thorough review of current marine pharmaceutical pipeline.

10 Huyck TK, Gradishar W, Manuguid F, Kirkpatrick P. Eribulin mesylate. Nat. Rev. Drug. Discov. 10,173-174(2011).

11 Blunt JW, Copp BR, Munro MH, Northcote PT, Prinsep MR. Marine natural products. Nat. Prod. Rep. 28, 196-268 (2011).

- Latest of a broad review series reporting newly identified marine natural products in a certain time period. This review also cites a number of specific reviews covering different aspects of marine natural product research such as specific biological activities, synthetic and biosynthetic studies.

12 Blunt JW, Copp BR, Munro MH, Northcote PT, Prinsep MR. Marine natural products. Nat. Prod. Rep. 27, 165-237 (2010).

13 Mayer AM, Rodríguez AD, Berlinck RG, Fusetani N. Marine pharmacology in 2007-2008: marine compounds with antibacterial, anticoagulant, antifungal, anti-inflammatory, antimalarial, antiprotozoal, antituberculosis, and antiviral activities; affecting the immune and nervous system, and other miscellaneous mechanisms of action. Comp. Biochem. Physiol. C. Toxicol. Pharmacol. 153, 191-222 (2011).
14 Mayer AM, Gustafson KR. Marine pharmacology in 2005-2006: antitumour and cytotoxic compounds. Eur. J. Cancer 44 , 2357-2387 (2008).

15 Singh R, Sharma M, Joshi P, Rawat DS. Clinical status of anti-cancer agents derived from marine sources. Anticancer Agents Med. Chem. 8, 603-617 (2008).

16 Sagar S, Kaur M, Minneman KP. Antiviral lead compounds from marine sponges. Mar. Drugs 8, 2619-2638 (2010).

17 Yooseph F, Sutton G, Rusch DB et al. The Sorcerer II Global Ocean Sampling Expedition: expanding the universe of protein families. PLoS Biol. 5, e16 (2007).

18 Miller H, Norton CN, Sarkar IN. GenBank and PubMed: how connected are they? BMC Res. Notes 2, 101 (2009).

19 Wolfe-Simon F, Blum JS, Kulp TR et al. A bacterium that can grow by using arsenic instead of phosphorus. Science 332, 1163-1166 (2011).

20 Thornburg CC, Zabriskie TM, McPhail KL Deep-sea hydrothermal vents: potential hot spots for natural products discovery? J. Nat. Prod. 73, 489-499 (2010).

21 Homann VV, Sandy M, Tincu JA, Templeton AS, Tebo BM, Butler A. Loihichelins A-F, a suite of amphiphilic siderophores produced by the marine bacterium Halomonas LOB-5. J. Nat. Prod. 72, 884-888 (2009).

22 Diyabalanage T, Amsler CD, McClintock JB, Baker BJ. Palmerolide A, a cytotoxic macrolide from the Antarctic tunicate Synoicum adareanum. J. Am. Chem. Soc. 128, 5630-5631 (2006). 
23 Schmidt EW. Trading molecules and tracking targets in symbiotic interactions. Nat. Chem. Biol. 4, 466-473 (2008).

24 Ireland CM, Durso AR, Newman RA, Hacker MP. Antineoplastic cyclic peptides from the marine tunicate Lissoclinum patella. J. Org. Chem. 47, 1807-1811 (1982).

25 Schmidt EW, Nelson JT, Rasko DA et al. Patellamide A and C biosynthesis by a microcin-like pathway in Prochloron didemni, the cyanobacterial symbiont of Lissoclinum patella. Proc. Natl Acad. Sci. USA 102, 7315-7320 (2005).

26 Davidson SK, Allen SW, Lim GE, Anderson CM, Haygood MG. Evidence for the biosynthesis of bryostatins by the bacterial symbiont "Candidatus Endobugula sertula" of the bryozoan Bugula neritina. Appl. Environ. Microbiol. 67, 4531-4537 (2001).

27 Trindade-Silva AE, Lim-Fong GE, Sharp KH, Haygood MG. Bryostatins: biological context and biotechnological prospects. Curr. Opin. Biotechnol. 21, 834-842 (2010).

28 Miljanic GP. Ziconotide: neuronal calcium channel blocker for treating severe chronic pain. Curr. Med. Chem. 11, 3029-3040 (2004).

29 McGiver JG. Targeting N-type and T-type calcium channels for the treatment of pain. Drug Discov. Today 11, 245-253 (2006).

30 Olivera BM. $\omega$-conotoxin MVIIA: from marine snail venom to analgesic drug. In: Drugs from the Sea. Fusetani N (Ed.). Karger Publishers, Basel, Switzerland 75-85 (2000).

31 D'Incalci M, Galmarini CM. A review of trabectedin (ET-743): a unique mechanism of action. Mol. Cancer. Ther. 9, 2157-2163 (2010).

32 Smith JA, Wilson L, Azarenko O et al. Eribulin binds at microtubule ends to a single site on tubulin to suppress dynamic instability. Biochemistry 49, 1331-1337 (2010).

33 Crews CM, Collins JL, Lane WS, Snapper ML, Schreiber SL. GTP-dependent binding of the antiproliferative agent didemnin to elongation factor 1a.J. Biol. Chem. 269, 15411-15414 (1994).

34 Chun HG, Davies B, Hoth D. Didemnin B. The first marine compound entering clinical trials as an antineoplastic agent. Invest. New Drugs 4, 279-284 (1986).

35 Simmons TL, Andrianasolo E, McPhail K, Flatt P, Gerwick WH. Marine natural products as anticancer drugs. Mol. Cancer Ther. 4: 333-342 (2005).

36 Hughes CC, MacMillan JB, Gaudencio SP, Fenical W, La Clair JJ. Ammosamides A and B target myosin. Angew. Chem. Int. Ed. 48, 728-732 (2009).
37 Ovechkina YY, Pettit RK, Cichacz ZA, Pettit GR, Oakley BR. Unusual antimicrotubule activity of the antifungal agent spongistatin 1. Antimicrob. Agents Chemother. 43, 1993-1999 (1999).

Bai R, Taylor GF, Cichacz ZA et al. The spongistatins, potently cytotoxic inhibitors of tubulin polymerization, bind in a distinct region of the vinca domain. Biochemistry 34, 9714-9721 (1995).

39 Schyschka L, Rudy A, Jeremias I, Barth N, Pettit GR, Vollmar AM. Spongistatin 1: a new chemosensitizing marine compound that degrades XIAP. Leukemia 22, 17371745 (2008).

40 Fenical W, Jensen PR, Palladino MA, Lam KS, Lloyd K, Potts BC. Discovery and development of the anticancer agent salinosporamide A (NPI-0052). Bioorg. Med. Chem. 17, 2175-2180 (2009).

41 Luesch H, Yoshida WY, Moore RE, Paul VJ, Corbett TH. Total structure determination of apratoxin A, a potent novel cytotoxin from the marine cyanobacterium Lyngbya majuscula. J. Am. Chem. Soc. 123, 5418 5423 (2001).

42 Liu Y, Law BK, Luesch H. Apratoxin A reversibly inhibits the secretory pathway by preventing cotranslational translocation. Mol. Pharmacol. 76, 91-104(2009).

43 Taori K, Paul VJ, Luesch H. Structure and activity of largazole, a potent antiproliferative agent from the Floridian marine cyanobacterium Symploca sp. J. Am. Chem. Soc. 130, 1806-1807 (2008).

44 Ying Y, Taori K, Kim H, Hong J, Luesch H. Total synthesis and molecular target of largazole, a histone deacetylase inhibitor. J. Am. Chem. Soc. 130, 8455-8459 (2008).

45 Fenical W, Jensen PR. Developing a new resource for drug discovery: marine actinomycete bacteria. Nat. Chem. Biol. 2, 666-673 (2006).

46 Molinski TF. Microscale methodology for structure elucidation of natural products. Curr. Opin. Biotechnol. 21, 819-826 (2010).

- Comprehensive review of the innovation in structure-determination techniques that enables microscale structure analysis.

47 Fellenberg M, Coksezen A, Meyer B. Characterization of picomole amounts of oligosaccharides from glycoproteins by $1 \mathrm{H}$ NMR spectroscopy. Angew. Chem. Int. Ed. Engl. 49, 2630-2633 (2010).

48 Searle PA, Molinski TF. Phorboxazoles A and B: potent cytostatic macrolides from marine sponge Phorbas sp. J. Am. Chem. Soc. 117, 8126-8131 (1995).
49 MacMillan JB, Xiong-Zhou G, Skepper CK, Molinski TF. Phorbasides A-E, cytotoxic chlorocyclopropane macrolides glycosides from the marine sponge Phorbas sp. CD determination of $C$-methyl sugar configurations. J. Org. Chem. 73, 3699-3706 (2008).

50 Dalisay DS, Molinski TF. Structure elucidation at the nanomole scale. 3. Phorbasides G-I from Phorbas sp. J. Nat. Prod. 73, 679-682 (2010).

51 Dalisay DS, Molinski TF. Structure elucidation at the nanomole scale. 2. Hemi-phorboxazole A from Phorbas sp. Org. Lett. 11, 1967-1197 (2009).

52 Dalisay DS, Morinaka BI, Skepper CK, Molinski TF. A tetrachloro polyketide hexahydro-1H-isoindolone, muironolide A, from the marine sponge Phorbas sp. Natural products at the nanomole scale. J. Am. Chem. Soc. 131, 7552-7553 (2009).

53 Gross L, Mohn F, Moll Net al. Organic structure determination using atomicresolutionscanning probe microscopy. Nat. Chem. 2, 821-825 (2010).

54 Wu PL, Hsu YL, Jao CW. Indole alkaloids from Cephalanceropsis gracilis . J. Nat. Prod. 69, 1467-1470 (2006).

55 Mason J, Bergman J, Janosik T. Synthetic studies of cephalandole alkaloids and the revised structure of cephalandole A. J. Nat. Prod. 71, 1447-1450 (2008).

56 Chan JN, Nislow C, Emili A. Recent advances and method development of drug target identification. Trends Pharmacol. Sci. 31, 82-88 (2010).

- Review discussing the improvement and advancement of drug-target identification techniques, pointing out the advantages and disadvantages of several approaches.

57 Hart CP. Finding the target after screening the phenotype. Drug Discov. Today 10, 513-519 (2005).

58 Luesch H. Towards high-throughput characterization of small molecule mechanisms of action. Mol. Biosyst. 2, 609-620 (2006).

59 Lomenick B, Olsen RW, Huang J. Identification of direct protein targets of small molecules. ACS Chem. Biol. 6, 34-46 (2011).

60 Lomenick B, Hao R, Jonai N et al. Target identification using drug affinity responsive target stability (DARTS). Proc. Natl Acad. Sci. USA. 106, 21984-21989 (2009).

61 Matsunaga S, Fusetani N, Hashimoto K, Walchli M. Theonallemide F - a novel antifungal bicyclic peptide from a marine sponge Theonella sp. J. Am. Chem. Soc. 111, 2582-2588 (1989). 
62 Matsunaga S, Fusetani N. Theonellamides A-E, cytotoxic bicyclic peptides, from a marine sponge Theonella sp. J. Org. Chem. 60, 1177-1181 (1995).

63 Nishimura S, Arita Y, Iwamoto K et al. Marine antifungal theonellamides target $3 \beta$-hydroxysterol to activate Rhol signaling. Nat. Chem. Biol. 6, 51-526 (2010).

- Remarkable application of drug-target identification techniques led to target identification of a marine antifungal drug as a novel class of sterolbinder.

64 Chen J, Forsyth CJ. Total synthesis of apratoxin A. J. Am. Chem. Soc. 125, 8734-8735 (2003).

65 Luesch H, Chanda SK, Raya RM et al. A functional genomics approach to the mode of action of apratoxin A. Nat. Chem. Biol. 2, 158-567 (2006).

66 Shen S, Zhang P, Lovchik MA et al. Cyclodepsipeptide toxin promotes the degradation of Hsp90 client proteins through chaperone-mediated autophagy. J. Cell. Biol. 185, 629-639 (2009).

67 Wender PA, Baryza JL, Brenner SE et al. Function oriented synthesis: the design, synthesis, PKC binding and translocation activity of a new bryostatin analog. Curr. Drug. Discov. Technol. 1, 1-11 (2004).

68 Smith AB 3rd, Tomioka T, Risatti CA, Sperry JB, Sfouggatakis C. Gram-scale synthesis of (+)-spongistatin 1: development of an improved, scalable synthesis of the F-ring subunit, fragment union, and final elaboration. Org. Lett. 10, 4359-4362 (2008).

69 Paterson I, Chen DY, Coster MJ, Aceña JL, Bach J, Wallace DJ. The stereocontrolled total synthesis of altohyrtin A/spongistatin 1: fragment couplings, completion of the synthesis, analogue generation and biological evaluation. Org. Biomol. Chem. 3, 2431-2440 (2005).

70 Heathcock CH, McLaughlin M, Medina J et al. Multigram synthesis of the C29-C51 subunit and completion of the total synthesis of altohyrtin C (spongistatin 2). J. Am. Chem. Soc. 125, 12844-12849 (2003).

71 Smith AB III, Risatti CA, Atasoylu O, Bennett CS, Tendyke K, Xu Q. Design, synthesis, and biological evaluation of EF- and ABEFanalogues of (+)-spongistatin 1. Org. Lett. 12, 1792-1795 (2010).

72 Hirata Y, Uemura D. Halichondrins antitumor polyether macrolides from a marine sponge. Pure Appl. Chem. 58, 701-710 (1986).

73 Bai RL, Paul KD, Herald CL, Malspeis L, Pettit GR, Hamel E. Halichondrin B and homohalichondrin $\mathrm{B}$, marine natural products binding in the vinca domain of tubulin. Discovery of tubulin-based mechanism of action by analysis of differential cytotoxicity data. J. Biol. Chem. 266, 15882-15889 (1991).

74 Aicher TD, Buszek KR, Fang FG et al. Total synthesis of halichondrin B and norhalichondrin B. J. Am. Chem. Soc. 114, 3162-3164 (1992).

75 Ledford H. Complex synthesis yields breast-cancer therapy. Nature 468, 608-609 (2010).

76 Long RA, Azam F. Antagonistic interactions among marine pelagic bacteria. Appl. Environ. Microbiol. 67, 4975-4983 (2001).

77 Cuevas C, Perez M, Martin MJ et al. Synthesis of ecteinascidin ET-743 and phthalascidin Pt-650 from cyanosafracin B. Org. Lett. 3, 2545-2548 (2000).

78 Cragg GM, Schepartz SA, Suffness M, Grever MR. The taxol supply crisis. New NCI policies for handling the large-scale production of novel natural product anticancer and anti-HIV agents. J. Nat. Prod. 56, 1657-1668 (1993).

79 Kolewe ME, Gaurav V, Roberts SC. Pharmaceutically active natural product synthesis and supply via plant cell culture technology. Mol. Pharm. 5,243-256 (2008).

80 Pettit RK. Mixed fermentation for natural product drug discovery. Appl. Microbiol. Biotechnol. 83, 19-25 (2009).

81 Oh DC, Jensen PR, Kauffman CA, Fenical W. Libertellenones A-D: induction of cytotoxic diterpenoid biosynthesis by marine microbial competition. Bioorg. Med. Chem. 13, 5267-5273 (2005).

82 Zhu F, Lin Y. Marinamide, a novel alkaloid and its methyl ester produced by the application of mixed fermentation technique to two mangrove endophytic fungi from the South China Sea. Chin. Sci. Bull. 51, 1426-1430 (2006).

83 Angell S, Bench BJ, Williams H, Watanabe CM. Pyocyanin isolated from a marine microbial population: synergistic production between two distinct bacterial species and mode of action. Chem. Biol. 13, 1349-1359 (2006).

84 Oh DC, Kauffman CA, Jensen PR, Fenical W. Induced production of emericellamides $\mathrm{A}$ and B from the marine-derived fungus Emericella sp. in competing co-culture. J. Nat. Prod. 70, 515-520 (2007).

85 Lane AL, Moore BS. A sea of biosynthesis: marine natural products meet the molecular age. Nat. Prod. Rep. 28, 411-428 (2011).

- Comprehensive review highlighting the importance of innovation in molecular biology and bioinformatics approaches to marine drug discovery, giving some remarkable examples.
86 Kittendorf JD, Sherman DH. Developing tools for engineering hybrid polyketide synthetic pathways. Curr. Opin. Biotechnol. 17, 597-605 (2006).

87 Roessner CA, Scott AI. Achieving natural product synthesis and diversity via catalytic networking ex vivo. Chem. Biol. 3, 325-330 (1996).

88 Cheng Q, Xiang L, Izumikawa M, Meluzzi D, Moore BS. Enzymatic total synthesis of enterocin polyketides. Nat. Chem. Biol. 3, 557-558 (2007).

89 Challis GL. Genome mining for novel natural product discovery. J. Med. Chem. 51, 2618-2628 (2008).

90 Udwary DW, Zeigler L, Asolkar RN et al. Genome sequencing reveals complex secondary metabolome in the marine actinomycete Salinispora tropica. Proc. Natl Acad. Sci. USA. 104, 10376-10381 (2007).

91 Feling RH, Buchanan GO, Mincer TJ, Kauffman CA, Jensen PR, Fenical W. Salinosporamide A: a highly cytotoxic proteasome inhibitor from a novel microbial source, a marine bacterium of the new genus Salinospora. Angew. Chem. Int. Ed. 115, 369-371 (2003).

92 Buchanan GO, Williams PG, Feling RH, Kauffman CA, Jensen PR, Fenical W. Sporolides A and B: structurally unprecedented halogenated macrolides from the marine actinomycete Salinispora tropica. Org. Lett. 7 , 2731-2734 (2005).

93 Aotani Y, Nagata H, Yoshida M. Lymphostin (LK6-A), a novel immunosuppressant from Streptomyces sp. KY11783: structural elucidation. J. Antibiot. 50, 543-545(1997).

94 Gulder TA, Moore BS. Chasing the treasures of the sea - bacterial marine natural products. Curr. Opin. Microbiol. 12, 252-260 (2009) and references therein.

95 Eustáquio AS, O’Hagan D, Moore BS. Engineering fluorometabolite production: fluorinase expression in Salinispora tropica yields fluorosalinosporamide. J. Nat. Prod. 73, 378-382 (2010).

96 Magarvey NA, Beck ZQ, Golakoti T et al. Biosynthetic characterization and chemoenzymatic assembly of the cryptophycins. Potent anticancer agents from Nostoc cyanobionts. ACS Chem. Biol. 1, 766-779 (2006).

97 Kobayashi M, Aoki S, Ohyabu N, Kurosu M, Wang W, Kitagawa I. Arenastatin A, a potent cytotoxic depsipeptide from the okinawan marine sponge Dysidea arenaria. Tetrahedron Lett. 35, 7969-7972.

98 Magarvey NA, Beck ZQ, Golakoti T, Ding Y, Huber U, Hemscheidt TK. Biosynthetic characterization and chemoenzymatic 
assembly of the cryptophycins. Potent anticancer agents from cyanobionts. ACS Chem. Biol. 1, 766-779 (2006).

99 Mortison JD, Sherman DH. Frontiers and opportunities in chemoenzymatic synthesis. J. Org. Chem. 75(21), 7041-7051 (2010).

100 Cheng Q, Xiang L, Izumikawa M, Meluzzi D, Moore BS. Enzymatic total synthesis of enterocin polyketides. Nat. Chem. Biol. 3, 557-558 (2007).
- Successful in vitro multienzyme synthesis of complex marine natural products increases optimism in overcoming the hurdles associated with one of the major challenges facing marine drug discovery.

101 Li MHT, Ung PM, Zajkowski J, GarneauTsodikova S, Sherman DH. Automated genome mining for natural products. $B M C$ Bioinformatics 10, 185 (2009).
102 Yadav G, Gokhale RS, Mohanty D. Towards prediction of metabolic products of polyketide synthases: an in silico analysis. PLoS Comput. Biol. 5, e1000351 (2009).

\section{- Website}

201 Census of Marine Life. www.coml.org 